\title{
Impact of COVID-19 and Renewed Awareness of Where We Could Improve
}

\section{Zheng Ye (Lan) Yang}

To cite this article: Zheng Ye (Lan) Yang (2022): Impact of COVID-19 and Renewed Awareness of Where We Could Improve, Journal of Library Resource Sharing, DOI: 10.1080/1072303X.2021.2009952

To link to this article: https://doi.org/10.1080/1072303X.2021.2009952

$$
\text { 曲 Published online: } 11 \text { Jan } 2022 .
$$

Submit your article to this journal $₫$

Џll Article views: 12

Q View related articles ๘

View Crossmark data ¿ 


\title{
Impact of COVID-19 and Renewed Awareness of Where We Could Improve
}

\author{
Zheng Ye (Lan) Yang \\ Texas A\&M University Libraries, College Station, Texas, USA
}

\begin{abstract}
The author compared the data of the fall semester of 2019 with the fall semester of 2020 to discern the impact of COVID 19 in terms of resource sharing, document delivery activities in a flagship academic institution. The author aims to find out: Was there a huge decrease in requests submission caused by COVID-19, even after we resumed regular resource sharing and in-house document delivery activities in the fall of 2020? Which user groups by status and department/college affiliation were the heavy users of the GIFM service before and during COVID19 ? Have patron's format preferences changed since COVID-19? How successful was the fill rate when we requested ebook from other libraries? How has our participation in HathiTrust emergency temporary access played a role in fulfilling some of the requests? What were our fill rates? What were the main cancelation reasons for requests in borrowing and lending? What was the percentage of requests canceled by customers after we received the items from other libraries? Was there any correlation between customer canceled requests and not meeting their "needed by" date? Were there any human errors for canceled requests that need staff attention? What was the ratio of requests filled by RapidILL vs. OCLC?
\end{abstract}

\section{KEYWORDS}

Ebook ILL; fill rates; format preference; impact of COVID-19; rapid vs OCLC; reasons for cancelation; resource sharing

\section{Introduction}

The global health crisis COVID-19 unexpectedly hit us in early 2020, like all the libraries and universities across the world, Texas A\&M University Libraries closed completely to public access from March 24 to June 30, 2020. Though the Libraries were closed, staff worked remotely from home, our branded document delivery and interlibrary loan service - Get It For Me (GIFM) was never completely shut down. Texas A\&M University Libraries' document delivery and interlibrary service team members were committed to continuing our support of the community's research, learning, and teaching endeavors. We filled requests from our electronic resources or outsourced from other libraries who were able to supply the requested 
items from their electronic collections. Our physical stacks were "roped off" and we required that our customers access and use the electronic copy in HathiTrust, if available. On July 1, 2020, we resumed book retrieval services requested via GIFM from our print collections and offered no-contact pickup of books for our customers. On the first day of fall semester, August 19 of 2020, we started borrowing physical items from other libraries and lending our own print books to other libraries. We created a page on our website entitled "What changes are there to Get It For $\mathrm{Me}$ / Interlibrary Loan due to the coronavirus pandemic." On that page, we stated that if our customers were taking all their classes online and their home address was not in College Station/Bryan (where the main campus of Texas A\&M University is located), we would use FedEx to send their requested books (if there is no ebook version available) to their home address with a prepaid return label. We strived to deliver consistent and excellent service in enabling the Libraries to maintain its mission to our campus in that unprecedented year.

Since 2010, request numbers of borrowing loan; borrowing article; in-house book retrieval (doc del loan); in-house document scanning (doc del article); lending loan; and lending article at Texas A\&M University Libraries have declined steadily as shown in Figure 1. This is in-line with the global trends reported by McGrath in his 2015 study (McGrath, 2015). It is not a surprise to see a steep drop of loan requests in 2020 due to libraries' closure during the first part of the pandemic when we suspended requesting or supplying physical items for almost five months. The decrease for in-house document scanning and borrowing article requests from other libraries in 2020 followed the steady trends, except for a slight uptick for lending article requests. Texas A\&M University Libraries had conducted three surveys regarding customer satisfaction and their awareness of the document delivery/interlibrary loan services we offered to them for free since 2002 (Yang, 2004; Yang et al., 2012, 2019). However, we never studied the data that we could easily generate from the interlibrary loan management system ILLiad to answer some of the questions that I, as the unit director, would like to know and this study tries to fill this gap. The

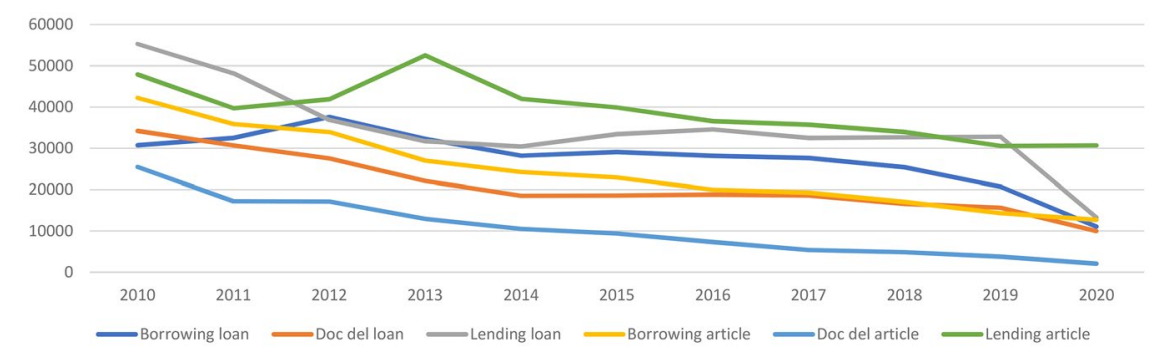

Figure 1. Requests trends in six categories from 2010 to 2020. 
author compared the data of the fall semester of 2019 (pre-COVID-19) with the fall semester of 2020 (during COVID-19) to find answers to the following questions:

Was there a huge decrease in requests submission caused by COVID19 , even after we resumed regular resource sharing and in-house document delivery activities in the fall of 2020? Which user groups by status and department/college affiliation were the heavy users of the GIFM service before and during COVID-19? Have patron's format preferences changed since COVID-19? How successful was the fill rate when we requested ebook from other libraries? How has our participation in HathiTrust emergency temporary access played a role in fulfilling some of the requests? What were our fill rates? What were the main cancelation reasons for requests in borrowing and lending? What was the percentage of requests canceled by customers after we received the items from other libraries? Was there any correlation between customer canceled requests and not meeting their "needed by" date? Were there any human errors for canceled requests that need staff attention? What was the ratio of requests filled by RapidILL vs. OCLC?

\section{Literature review}

There is no published paper yet that has addressed the impact of COVID19 in resource-sharing. However, quite a few studies had been conducted reporting resource sharing activities trends. Grevatt reported Boise State University's case that "by looking at factors such as usage patterns, new user registrations, and cancelation language, the decrease in borrowing and lending requests was confirmed and attributed primarily to decrease in graduate student ILLiad registrations and a lending ebook deflection implemented in 2015" (Grevatt, 2015, p. 117). Kappus combined data analysis and trend analysis to explain increased borrowing request rates at Gonzaga University (Kappus, 2009). Atkins, et al. reported a slight 2\% decrease in the average number of total requests between 2010 and 2013 among the Association of Southeastern Research Libraries (Atkins et al., 2014). Through interviews with "thought leaders in resource sharing," Birch, et al. recorded that some institutions were experiencing increases in requests while others experienced decreases (Birch et al., 2013). Regardless of what the current trends appear to say about usage, Little and Leon's comparative study validated the fact that patrons find significant value in resource sharing services (Little \& Leon, 2015). This sentiment was echoed by Texas A\&M University customers who responded to Yang's surveys (Yang et al., 2019).

Several studies devoted to unfilled requests have been published. Gibson analyzed University of Arkansas lending canceled requests for the fiscal year of 2005-2006. She focused on what resource-sharing practitioners 
can do to improve lending fill rates at the micro level and what can be done at the macro level. She further explained why we should care about improving lending fill rates (Gibson, 2008). Zambri and Visser conducted an in-depth analysis of the unfilled requests in one of South Africa Library consortia for a period of three months. They reviewed each unfilled request from requesting point of view as well as supplying point of view. They offered remedial actions to each reason for cancelation. They concluded that "the fill rate of requests are determined by the quality of work, the quantity of items requested, and effectiveness of staff within service units, along with sufficient staff capacity and their levels of experience" (Zambri \& Visser, 2007, p.1). Leykam utilized College of Staten Island library's ILL data from November 2005 to October 2008 to get a clear picture of her library's lending practices and reasons why her staff has canceled ILL requests to outside institutions. She reported that $11 \%$ of the denials were attributed to staff errors, another $18 \%$ were denied without providing a clear reason. Her review of the data resulted in a complete retraining and reassignment of staff to improve the workflow of the ILL office (Leykam, 2009).

In the last decade, many studies reported the main barrier to ebook ILL was the licensing restriction on ILL by many ebook vendors and publishers (Litsey \& Ketner, 2013; Walters, 2014). When ebook ILL was allowed, usually only chapters could be shared (Machovec, 2015); sharing entire book versions was "still a struggle and nearly impossible" (Radnor \& Shrauger, 2012, p.156). Zhu reported that "more recently, the long-cherished tradition of ILL has been challenged," more and more academic libraries "are adopting user-based e-book purchasing models that have the potential to bypass ILL" (Zhu, 2018, p. 343).

This study confirmed some of the similar findings reported in the literature and shared some data that has never been reviewed and discussed before.

\section{Findings}

\section{Number of requests received in the fall of 2019 vs. the fall of 2020}

Figure 2 displays number of requests received in the fall of 2019 and the fall of 2020. It reveals fewer loan requests across all three functions in the fall of 2020. Most notably both borrowing loan requests and lending loan requests were down by $48 \%$, and $47 \%$ respectively compared to the fall of 2019 numbers. In-house book retrieval requests (doc del loan) in the fall of 2020 were down by $16 \%$. For article requests, lending had a slight increase of $5 \%$ in the fall of 2020, while both borrowing and in-house scanning requests (doc del article) were down by $26 \%$ and $38 \%$ respectively 


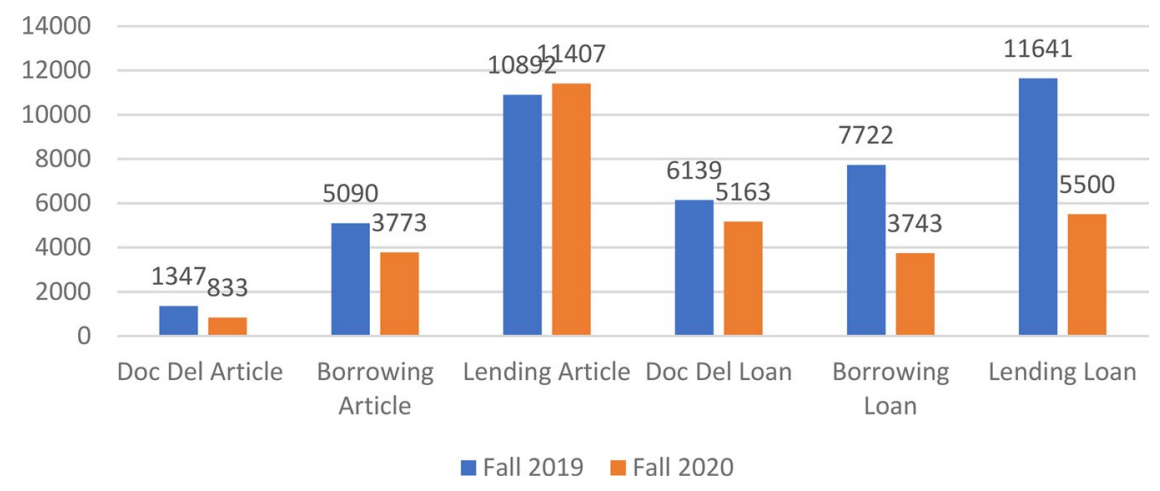

Figure 2. Number of requests received in borrowing, lending, and in-house document delivery.

in the fall of 2020. Such large percentage drop in five categories were not seen before.

\section{Who used the get it for me service}

GIFM is our free document delivery and interlibrary loan service offered to our current campus population of 75,000 customers regardless of their academic status. 99,513 Texas A\&M University Libraries customers have registered and used this service since June 2002. In our Libraries' catalog, the "Get It" button is shown for item either available in our collections "Get It: 2-3 days" or currently checked out "Get It: 4-7 days." If the item is available, we retrieve the item for our customer, saving them a trip to the Libraries. If the item is checked out, we request it from other libraries for our customers. The "Get It" button is displayed in the Texas A\&M University Libraries WorldCat subscription. The "Get It" button is also shown in our link resolver SFX if fulltext article is not available. However, if the item is in our Course Reserve or Special collection, we suppress the "Get It" button in the Libraries' catalog.

\section{Borrowing loans from other libraries by status}

In the fall of 2019, there were 2,682 patrons who submitted GIFM loan requests, where either our copies were checked out or we did not own them. In the fall of 2020, only 1,581 patrons submitted GIFM returnable requests, a sharp decrease of $41 \%$. Graduate students were dominant users, followed by undergraduate students, and faculty members as shown in Figure 3.

\section{Requesting articles from other libraries by status}

Far fewer patrons submitted GIFM article or chapter requests that we had to get from other libraries. In the fall of 2019 , there were 1,123 patrons 


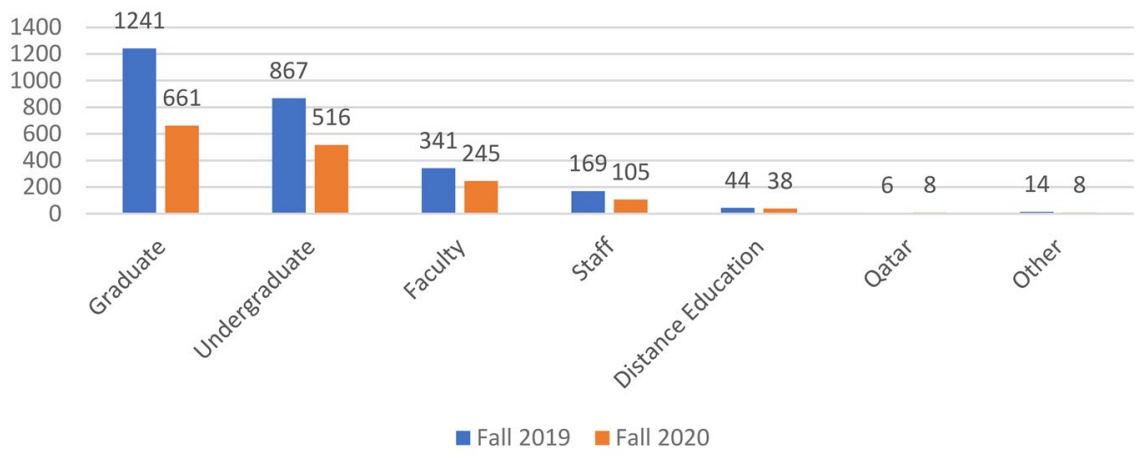

Figure 3. Number of patrons requested borrowing Loans from other libraries by status.

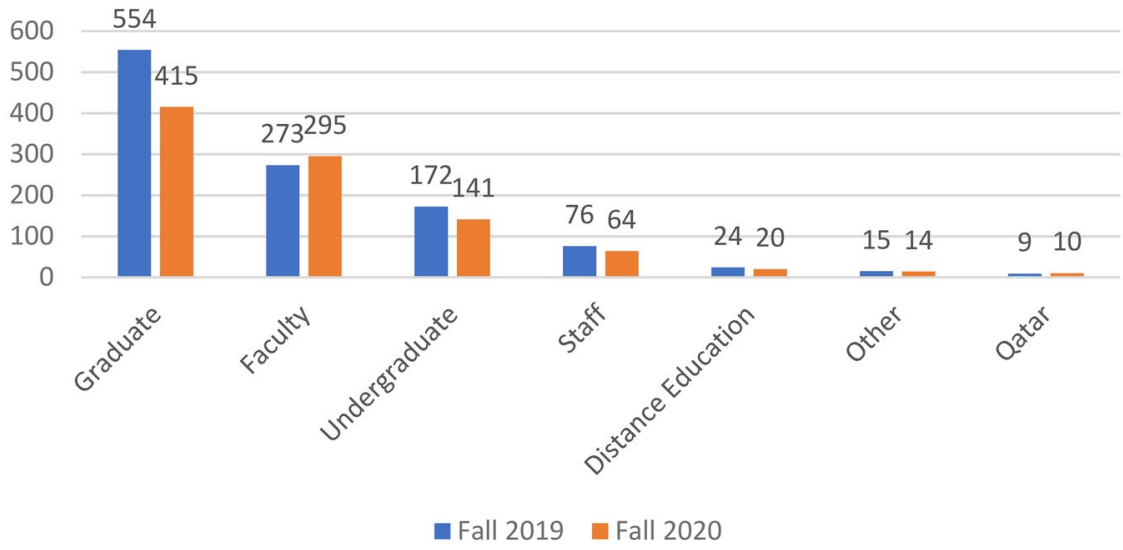

Figure 4. Number of patrons requested borrowing articles from other libraries by status.

who made such requests, but in the fall of 2020 , down to 959 patrons, a decrease of $15 \%$. Graduate students still led the pack, followed by faculty members, and undergraduate students. There were 22 more faculty who asked for this service in the fall of 2020 than they did in the fall of 2019 as illustrated in Figure 4.

\section{Requesting book retrieval and placing holds from Texas A\&M University}

\section{libraries stacks by status}

Total number of individuals who needed us to retrieve books from our stacks and place a hold for them to pick up at their library of choice remained almost the same in the fall of 2019 and the fall of 2020, and this service includes delivery to faculty/staff members' campus mailbox via the campus mail service. There were a mere seven more patrons requesting this service in the fall of $2020(1,727)$ than in the fall of 2019 $(1,720)$. However, we saw an increase of number of undergraduate students, 


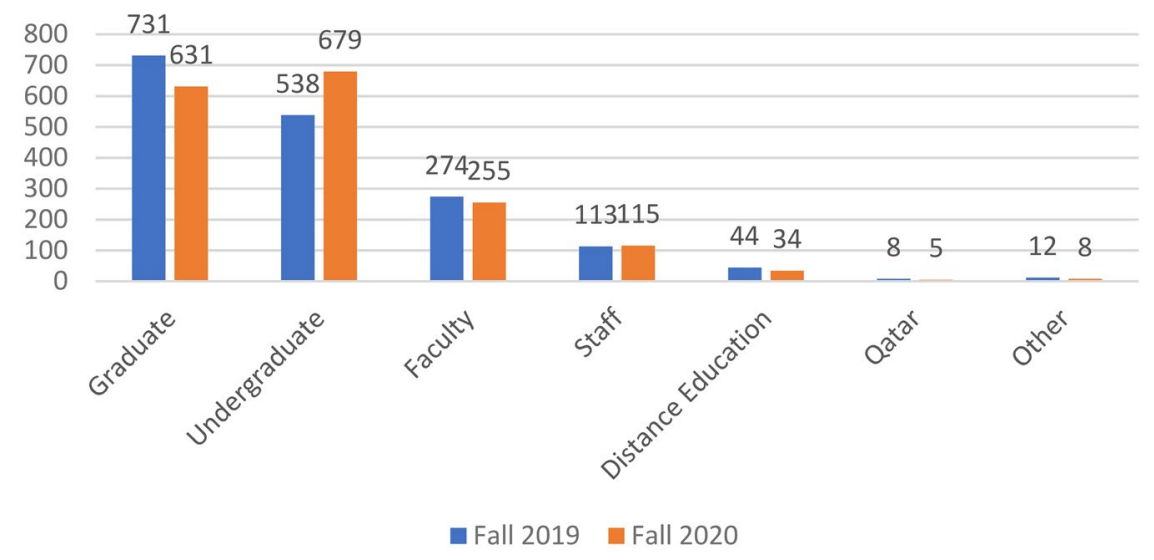

Figure 5. Number of patrons requested doc del loans by status.

by 141 (or 26\%), who requested the book retrieval service in the fall of 2020 than in the fall of 2019. Undergraduate students were the top users of this service in the fall of 2020, while graduate students led in the fall of 2019, and faculty members came in third in both fall semesters as shown in Figure 5.

Requesting scanning from Texas A\&M University libraries collections by status Number of patrons requesting for in-house chapter/article scanning were low. This is a positive sign, indicating our electronic resources are comprehensive to meet our customers' needs. As reported in Yang et al. (2019) survey, patrons indicated that they could find most of what they need from the internet or from the Texas A\&M University Libraries' databases (Yang et al., 2019). There was a total of 499 patrons asking for this service in the fall of 2019, but dropped to 356 in the fall of 2020, a decrease of $28.6 \%$. However, the number of faculty and staff members who used this service remained the same for both fall semesters as shown in Figure 6. Graduate students were again the top users for this service.

\section{Users of the service by college affiliation}

Top three colleges in terms of enrollment size at Texas A\&M University University are College of Engineering, College of Liberal Arts, and College of Agriculture \& Life Sciences. The author wanted to know if the top three groups of patrons who used the GIFM service were in this order. The data revealed that patrons from College of Liberal Arts were the top users, followed by College of Engineering, and College of Education in both fall of 2019 and fall of 2020. Patrons from the College of Agriculture \& Life Sciences came in fourth with their need for articles but ranked 


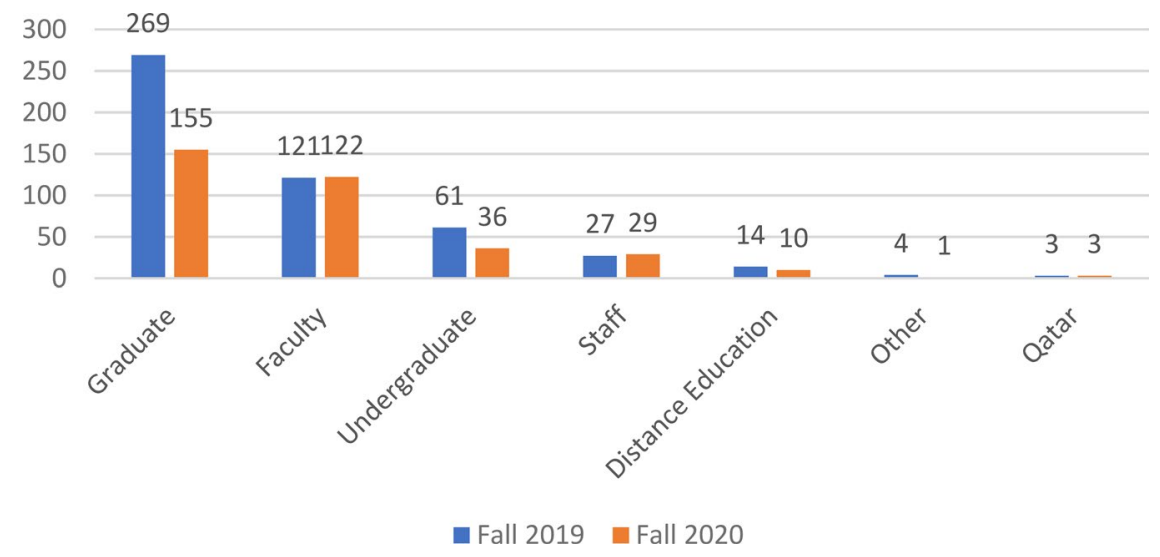

Figure 6. Number of patrons requested doc del articles by status.

sixth in their demand for loan requests. The data also showed that patrons affiliated with each of x's 14 colleges on the main campus used the service in both fall semesters of 2019 and 2020. The data further displayed that our customers in our middle east campus Qatar also used the GIFM in both fall semesters of 2019 and 2020, as shown in Figures 3-6.

\section{Format preferences}

The author conducted two surveys in the past asking over 70,000 Texas A\&M University customers about their format preferences. Both studies reported less than $20 \%$ of the responding patrons preferred eBook (Yang et al., 2012, 2019). During the pandemic, it would not surprise the author that we could see a change of format preferences when our patrons submitted the loan requests regardless of if owned by Texas A\&M University libraries or not. Data confirmed the author's assumption as shown in Figure 7 . In the fall of $2019,93 \%(12,855$ out of 13,858$)$ of the requests were print book preferred, only 6\% (807) were ebook preferred. In the fall of 2020, requests for ebook preferred were increased to $32 \%$ (2834 out of 8899).

\section{Ebook fill rate}

Ebook fill rate was still very low, only $18 \%$ in the fall of 2019 , but it has been improved to $31 \%$ in the fall of 2020 . Our participation in the HathiTrust Emergency Temporary Access Services from May 2020 to June 2021 has somewhat contributed to this improved fill rate. We are still a long way from successfully getting our ebook loans filled from other libraries using ILLiad/OCLC platform or via Occam's Reader as revealed 


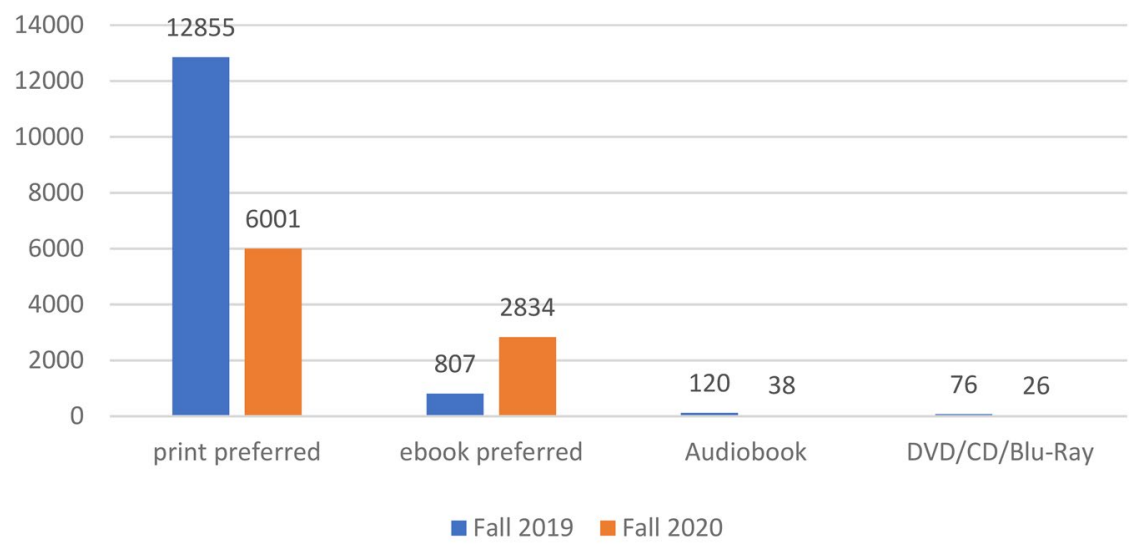

Figure 7. Format preference.

Table 1. Filled ebook by different venues.

\begin{tabular}{lcc}
\hline Ebook filled by venue & $\begin{array}{c}\text { Fall } 2019 \text { (146 ebooks were filled: } \\
18 \% \text { out of } 807 \text { ebook requests) }\end{array}$ & $\begin{array}{c}\text { Fall } 2020 \text { (878 ebooks were filled: } \\
31 \% \text { out of } 2834 \text { ebook requests) }\end{array}$ \\
\hline OCLC Libraries & $5(3 \%)$ & $17(2 \%)$ \\
Occam's reader & $10(7 \%)$ & $8(1 \%)$ \\
From internet archive & $18(12 \%)$ & $258(29 \%)$ \\
$\begin{array}{l}\text { Purchased by Texas A\&M University } \\
\text { Libraries }\end{array}$ & $113(78 \%)$ & $419(48 \%)$ \\
HathiTrust Emergency Access & N/A & $176(20 \%)$ \\
\hline
\end{tabular}

in Table 1. Occam's Reader is a system that allows interlibrary loan of electronic books. It was first developed as a collaborative project led by Texas Tech University, the University of Hawaii at Manoa and the Greater Western Library Alliance. Most of the ebook requests that we were able to fill for our patrons were in fact purchased by Texas A\&M University Libraries to honor their format preference, even though Texas A\&M University Libraries have a print version of the requested title. As reported by Zhu and Shen in their survey of e-book interlibrary loan policy in US academic libraries, "PDA (patron driven acquisition) has become an increasingly popular solutions to, if not yet a common substitute for, ebook ILL." They further commented "...not all ILL librarians seem to be knowledgeable about the license terms on ILL in different e-book packages and/or willing and able to negotiate the necessary permissions." Their survey data indicate that "e-book ILL has not become a common practice in US academic libraries, especially ILL with whole e-books" (Zhu \& Shen, 2014, p. 62).

\section{Fill rate}

Our in-house book retrieval and book chapter/article scanning fill rates were very high and consistent when comparing data from the fall of 2019 
to data from the fall of 2020 , they were at $96 \%$ vs. $95 \%$ for returnable; and $97 \%$ vs. $96 \%$ for non-returnable, respectively.

Fill rate for articles supplied by other libraries to us were very impressive, at $92 \%$ in the fall of 2019 and $98 \%$ in the fall of 2020 . Our borrowing loan requests fill rate was $85 \%$ in the fall of 2019 . With many libraries closed during the pandemic, it was reasonable to expect a lower fill rate for the loans in the fall of 2020, at 78\%. After all, our borrowing fill rates were comparable to Grevatt's study that their "fill rates for borrowing steadily increased to an impressive 94\% fill rate for articles and an $87 \%$ fill rate for loans"(Grevatt, 2015, p. 124). Overall, "borrowing fill rates generally hover around 80 to $90 \%$ " as Gibson noted in her report (Gibson, 2008, p. 385).

Looking at our lending fill rate, we saw an improvement for loan requests fill rate, from 55\% in the fall 2019 to $60 \%$ in the fall 2020 . But a decreased lending fill rate for article requests from $68 \%$ in the fall of 2019 to $59 \%$ in the fall of 2020. These lending fill rates were on par with Leykam's 59\%, slightly higher than Seaman's 50\% but falls short of the $73 \%$ fill rates cited in Gibson's (2008) article (Gibson, 2008; Leykam, 2009; Seaman, 1992).

\section{Canceled requests}

\section{Borrowing loans reasons for cancelation}

ILLiad has a customizable reason for cancelation table that we use to record and communicate with our patrons. If patrons canceled their requests, they are automatically routed into a queue named "canceled by customer." Staff members would then process those requests by first checking if the requests are already submitted to other libraries, if so, they would deal with them accordingly, and choose the reason "this request was canceled by the customer" from the cancelation table to complete the process. We canceled some of the requests for other reasons. The author wanted to know which top three reasons we used the most for cancelation. As revealed in Figure 8, "this request was canceled by the customer" and "we exhausted all possible resources" were the top two cancelation reasons for both 2019 and 2020 fall semesters. In the fall of 2020, the third most used reason was "we cannot circulate the print copy" due to our participation with HathiTrust's Emergency Temporary Access Service (ETAS). With the latter canceled reason, patrons specified that they would only accept the print version. If we did not participate in HathiTrust's ETAS, those requests would have been routed to the Doc Del module for retrieval and checkout. Technically those canceled requests should have been counted as one of our Doc Del reasons for cancelation. However, all "Get It" requests are first imported into our Illiad Borrowing module, processed and then transferred to the Doc Del Module if found in our collections. In fall 2020, we just canceled those HathiTrust titles as Borrowing requests. 


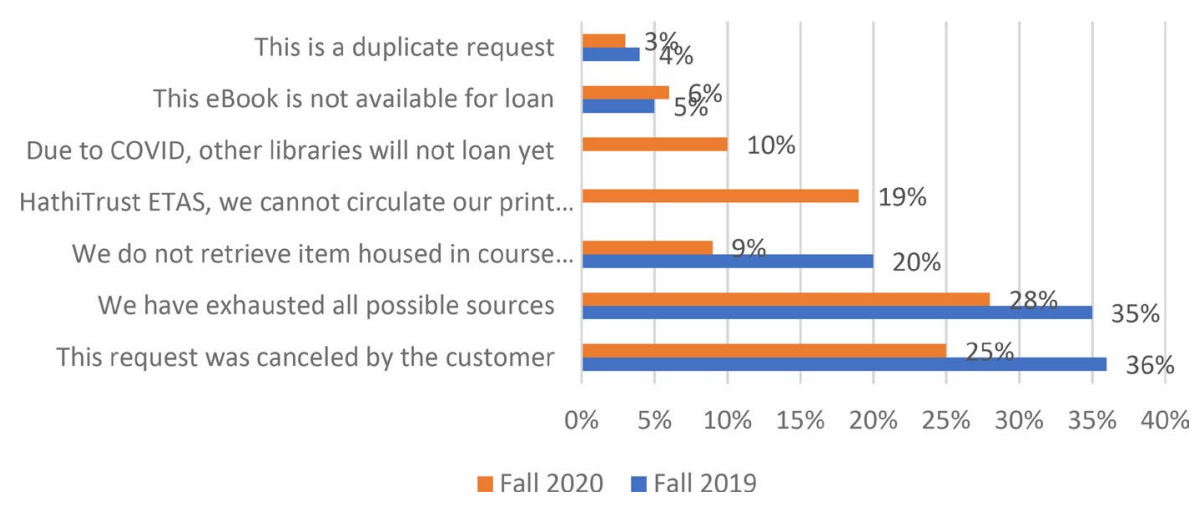

Figure 8. Borrowing loans reasons for cancellation $N=1403$ (Fall 2019) $N=940$ (Fall 2020).

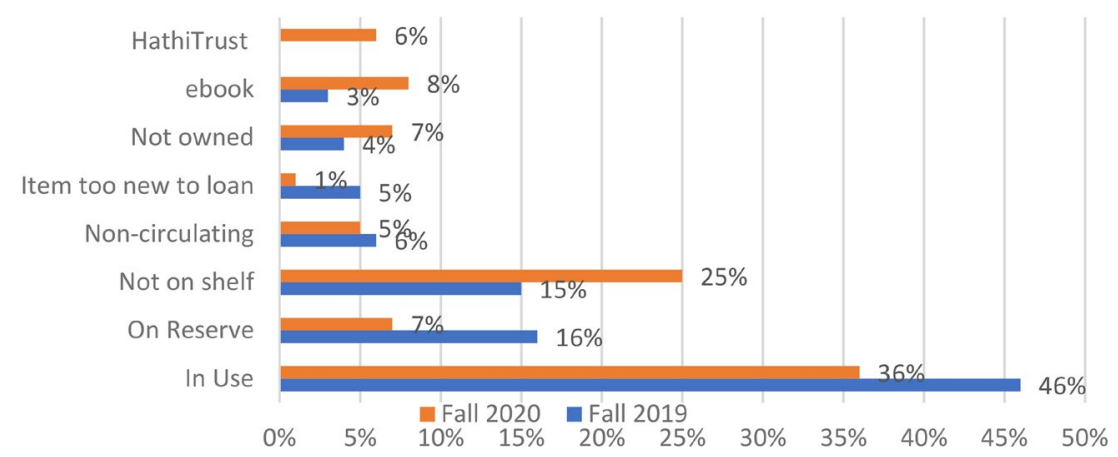

Figure 9. Lending loans reasons for cancellation $N=4916$ (Fall 2019) $N=2072$ (Fall 2020).

The author further analyzed the loan requests that were canceled by the customers. She wanted to find out how many books had been shipped by the lenders after the requests were canceled by the patrons. It turned out that in the fall of 2019 , only $2.6 \%$ (164 out of 6221 ) of the books that we received from other libraries were canceled by the patrons. In the fall of 2020, 2.9\% (56 out of 1960) of the books were shipped and supplied to us, but our customers canceled them afterwards. Even though the "canceled after received" rate was below 3\%, the author still assessed if there was any correlation between "customer canceled requests" and not meeting their "needed by" date? The analysis of those requests did not suggest any such correlation existed.

\section{Lending loans reasons for cancelation}

Like University of Arkansas' study (Gibson, 2008), the most prominent reason that we canceled our lending loan requests was because the requested items were "in use," representing by $46 \%$ of the canceled requests in the fall of 2019 and $36 \%$ in the fall of 2020 . Figure 9 lists the top five lending loan cancelation reasons. 


\section{Lending articles reasons for cancelation}

Looking at the lending article requests that Texas A\&M University Libraries canceled, the number one reason was "lacking volume," representing 45\% of the cancelation in the fall of 2019 and 39\% in the fall of 2020. The second reason for cancelation was "policy problem," representing $17 \%$ in the fall of 2019 and $19 \%$ in the fall of 2020 . This high percentage of cancelation citing "policy problem" prompted the author to examine further for each "policy problem" canceled request. She found that in many instances, in the pursuit of speedy response for an impressive turnaround time, some of the staff members failed to take time to navigate and look deeper into our resources to find the requested document. They simply chose "policy problem" as a default cancelation reason. To better reflect the true reasons for cancelation, the author recoded each "policy problem" canceled request and removed the "policy problem" as a reason for cancelation. The author also included "staff error" in Figure 10 as one of the remaining reasons for cancelation. Those canceled requests due to "staff error" should have been filled. Staff errors in processing were reported in both Gibson and Leykam's studies (Gibson, 2008; Leykam, 2009). We receive many lending requests via RapidILL, it automatically verifies journal ownership at the volume level prior to forwarding the request to the lenders. It does not seem to be right that we had such a high cancelation rate citing "lacking volume" either. More coaching and trainings need to be conducted to help team members find the document in our growing electronic resources and choose the correct reason for cancelation. As Gibson persuasively wrote that "we cannot expect other libraries to work hard to fill our requests if we are not willing to do the same" (Gibson, 2008, p. 384).

\section{Requests filled by OCLC vs. Rapid}

$x$ Libraries joined RapidILL in 2007. We have received and supplied articles to other Rapid members via the RapidILL for more than 14 years. Texas

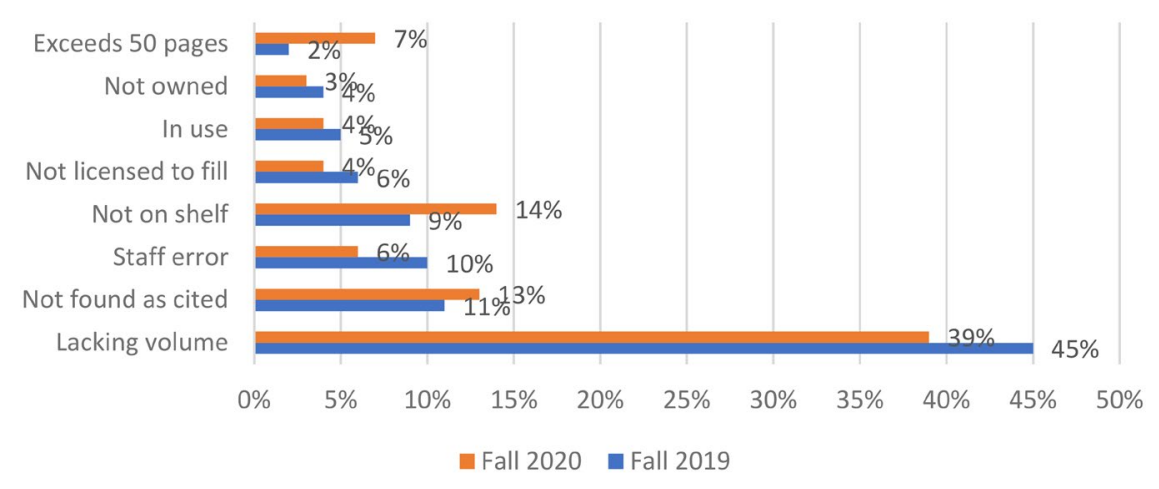

Figure 10. Lending articles reasons for cancellation $N=3470$ (Fall 2019) $N=4573$ (Fall 2020). 


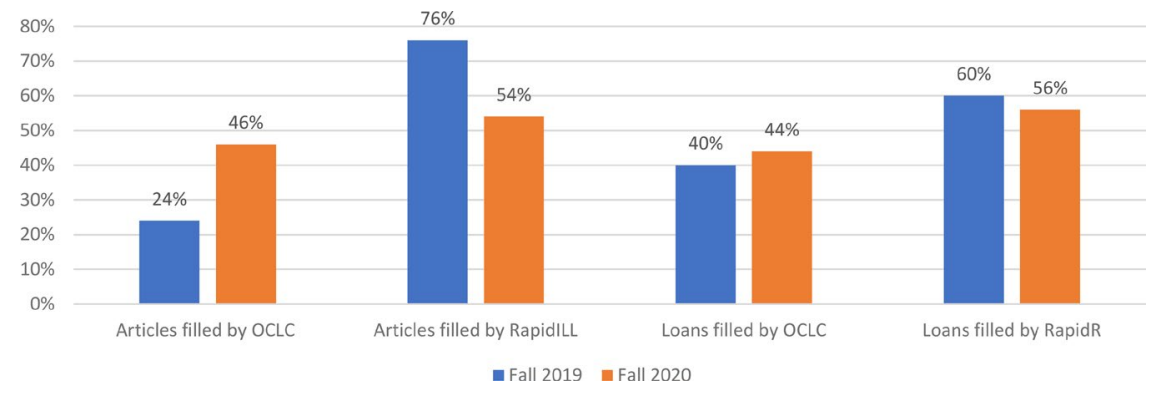

Figure 11. Requests filled by Rapid vs OCLC.

A\&M University Libraries is a member of Greater Western Library Alliance (GWLA). In 2018, GWLA members agreed to use Rapid's loan platform, commonly known as RapidR, as a preferred loan delivery mechanism among members. Out of 39 GWLA members, 31 participate in RapidR, we all commit to a 16-week loan period. Starting in January 2020, Texas A\&M University Libraries joined another 31 RapidR participants, this has increased our chances of receiving loans via RapidR because participating libraries now total 62 members. The author wanted to find out how many of our requests were filled in Rapid and how many we had to request from OCLC Worldshare ILL because our rapid subscription fee was only $7 \%$ of what we paid OCLC. We set a routing rule to have Rapid auto process the requests if ISSNs or ISBNs are included in the request form. Figure 11 displays the requests filled by these two systems in the fall of 2019 vs. the fall of 2020. The filled borrowing loan ratio for the fall of 2019 of RapidR vs. OCLC was 3:2. In the fall of 2020, the filled loan ratio of the two systems was close to half and half, with RapidR filled $12 \%$ more still. Many of our GWLA consortia members remained as a non-supplier for their physical items until the summer of 2021, this certainly affected our borrowing loan fill rate in RapidR. Looking at the article requests, the filled ratio of RapidILL vs. OCLC was 3:1 in the fall of 2019, the filled ratio was also close to half and half in the fall of 2020, RapidILL filled $8 \%$ more of the article requests. The author explored the filled data further and recognized that some staff members did not use Rapid as our preferred borrowing submission platform when patron failed to include ISSN or ISBN in the request form. Instead of using the Rapid addon in the ILLiad client to check availability in Rapid libraries first, they just submitted the requests via ILLiad/OCLC instead. If we had tried everything via the Rapid first, the percentage of loan requests that could have been filled by RapidR would have been increased to 65\% for both the fall of 2019 and the fall of 2020 semesters. For article requests, RapidILL could have filled $79 \%$ of our fall 2019 requests and $75 \%$ of the fall of 2020 requests. 


\section{Conclusion}

This limited local study and data analysis focusing on two fall semesters, one pre-COVID-19 and one during the COVID-19 answered the questions to satisfy the curiosity of the unit director. Data affirms that COVID-19 disrupted scholars and students' research and learning plans, this was manifested in the significant reduction of their request's submission in the fall of 2020. Graduate students used the GIFM service the most. It appears that undergraduate students' demand for article/chapter scanning from our own collections were very low, it might suggest that most of their needs could be found in our databases and the internet. Patrons from the college of liberal arts submitted more GIFM requests than any other colleges' patrons. COVID-19 somewhat changed patrons' format preference, we saw an increase of "ebook preferred" or "ebook only" requests in the fall of 2020 by fivefold. Nevertheless, we are still a long way from successfully getting our ebook loans filled. Our borrowing loan fill rate was comparable to many other libraries' reported in the literature, while our lending fill rate could have been improved. The top two cancelation reasons for borrowing requests were "this request was canceled by the customer" and "we have exhausted all the possible resources." The top cancelation reason for lending returnable was "in use" and "lacking volume" for nonreturnable.

Through this study, the author recognized some training needs for our staff members. Some of them whose productivity was so impressive, they just focused on moving the requests forward. However, when they stumbled on a difficult request, instead of seeking help, they passed it on to the next library. Realizing some training deficiency, the author who is the director of the unit, asked the unit supervisor to implement a daily mini coaching session with some of the staff members. Instead of canceling the requests that they could not find right away, they now would go to the supervisor and work with the supervisor to figure it out together. Both supervisor and staff members have enjoyed this daily exercise. They felt this has enhanced team building and energized collaboration with the spirit of getting it right. The supervisor would also spot check canceled requests that cited "lacking volumes." Occasionally, she found our e-journal holding information uploaded to RapidILL was not up to date. She would then report this to the RapidILL team for correction.

The author has also reminded her team members to always try to have Rapid fill our borrowing requests first. It is disheartening and frustrating to realize that the cost of OCLC services is almost 15 times the cost of Rapid, and less than half of our requests were filled by OCLC. To be exact, in FY 2020, we paid $\$ 134,675$ to OCLC WorldShare ILL, while our subscription fee to RapidILL was $\$ 9,222$. It is not unreasonable to point 
out that OCLC's pricing model is not sustainable for some libraries. As library budgets continue to stretch, Grevatt predicted that "it is logical and reasonable that more institutions are moving to local and regional consortiums... or borrowing exclusively from reciprocal partners" (Grevatt, 2015, p. 129). Several libraries have now stopped using OCLC WorldShare ILL to process their resource sharing requests, instead they rely on shared catalog with consortia members and other ISO compliant systems.

With ReShare on the horizon, an open-source resource sharing platform that is library-developed, owned, and managed with commercial organizations as partners that supports discovery, fulfillment, and delivery workflows, we are not sure how long we would continue using the OCLC services, if their pricing model does not change. This huge pricing difference will motivate the author to further evaluate and determine our future commitment to different resource sharing management systems available.

It will be an interesting study to evaluate which might be more cost effective: to purchase RapidILL and RapidR unfilled items as part of strategic collections, or to request those unfilled items from other libraries using OCLC Worldshare ILL platform.

With a continued downward requests trends, the director of the unit gave up another position when a team member retired in March 2020. The unit's FTE staff numbers were at peak of 13 in 2008 down to nine now, and our student workers were also reduced from 18 to 4 .

This local study is a way to show that as a director/head/manager of a resource sharing department, we need to periodically use the data available to us to detect progress or decline, evaluate the need of training as well as the assessment of staffing level and to act appropriately. When we review data, we need to "understand that a more detailed analysis can highlight further areas where improvement might be warranted" as Leykam wrote (Leykam, 2014).

\section{ORCID}

Zheng Ye (Lan) Yang (D) http://orcid.org/0000-0001-6757-7822

\section{References}

Atkins, D. P., Greenwood, J. T., \& Whaley, P. (2014). Benchmarking and pondering ASERL interlibrary loan operations, 2010 and 2013. Interlending \& Document Supply, 42(1), 16-25. https://doi.org/10.1108/ILDS-01-2014-0010

Birch, K. J., Goldner, M., \& Parson, K. N. (2013). Seven degrees of interlibrary lending. Interlending \& Document Supply, 41(1), 12-17. https://doi.org/10.1108/02641611311313034

Gibson, T. (2008). Cancelled requests: A study of interlibrary lending. Journal of Access Services, 5(3), 383-389. https://doi.org/10.1080/15367960802170761 
Grevatt, H. (2015). Developing a data narrative: Analyzing trends in an academic interlibrary loan department. Journal of Interlibrary Loan, Document Delivery \& Electronic Reserve, 25(3-5), 117-132. https://doi.org/10.1080/1072303X.2016.1180338

Kappus, T. (2009). Interlibrary loan tsunami: Investigating the rising tide of borrowing requests at a small private university. Journal of Interlibrary Loan,Document Delivery \& Electronic Reserve, 19(3), 205-217. https://doi.org/10.1080/10723030903031591

Leykam, A. (2009). Collateral damage: Interlibrary loan lending denials. Journal of Access Services, 6(4), 446-458. https://doi.org/10.1080/15367960903103414

Leykam, A. (2014). The devil is in the details: Exploring individual usage of interlibrary loan. Journal of Access Services, 11(1), 30-43. https://doi.org/10.1080/15367967.2014.87 6275

Litsey, R., \& Ketner, K. (2013). On the possibilities: Ebook lending and interlibrary loan. Interlending \& Document Supply, 41(4), 120-121. https://doi.org/10.1108/ILDS-09-20130027

Little, M., \& Leon, L. (2015). Assessing the value of ILL to our users: A comparative study of three US libraries. Interlending \& Document Supply, 43(1), 34-40. https://doi. org/10.1108/ILDS-10-2014-0051

Machovec, G. (2015). Consortial e-resource licensing: Current trends and issues. Journal of Library Administration, 55(1), 69-78. https://doi.org/10.1080/01930826.2014.985900

McGrath, M. (2015). A review of changes in the delivery of information to users: 12 years of literature reviews in interlending \& document supply. The Bottom Line, 28(1/2), 70-76. https://doi.org/10.1108/BL-12-2014-0031

Radnor, M. M., \& Shrauger, K. J. (2012). Ebook resources sharing models: Borrow, buy, or rent. Journal of Interlibrary Loan,Document Delivery \& Electronic Reserve, 22(3-4), 155-161. https://doi.org/10.1080/1072303X.2012.728186

Seaman, S. (1992). An examination of unfilled OCLC lending and photocopy requests. Information Technology and Libraries, 11(3), 229-235.

Walters, W. H. (2014). E-books in academic libraries: Challenges for sharing and use. Journal of Librarianship and Information Science, 46(2), 85-95.

Yang, Z. Y. (2004). Customer satisfaction with interlibrary loan service - deliverEdocs: A case study. Journal of Interlibrary Loan, Document Delivery \& Information Supply, 14(4), 79-94. https://doi.org/10.1300/J110v14n04_07

Yang, Z. Y., Goodwin, S. G., Hahn, D. (2019). Survey says...?: Assessing interlibrary loan/ document delivery use and awareness for responsive service delivery. Journal of Interlibrary Loan, Document Delivery \& Electronic Reserve, 28(5), 151-173. https://doi. org/10.1080/1072303X.2020.1752877

Yang, Z. Y., Hahn, D., \& Thornton, E. (2012). Meeting our customers' expectations: A follow-up customer satisfaction survey after 10 years of free document delivery and interlibrary loan services at Texas A\&M University Libraries. Journal of Interlibrary Loan,Document Delivery \& Electronic Reserve, 22(2), 95-110. https://doi.org/10.1080/1 072303X.2012.708390

Zambri, J., \& Visser, H. (2007). Lifting the curtain on unfilled interlibrary loan requests. In World Library and Information Congress: 73rd IFLA General Conference and Council, 19-23 August, 2007, South Africa.

Zhu, Z. (2018). E-book ILL in academic libraries: A three-year trend report. The Journal of Academic Librarianship, 44(3), 343-351. https://doi.org/10.1016/j.acalib.2018.03.006

Zhu, X., \& Shen, L. (2014). A survey of e-book interlibrary loan policy in US academic libraries. Interlending \& Document Supply, 42(2/3), 57-63. 